\title{
Reversibility and reproducibility of histamine induced plasma leakage in nasal airways
}

\author{
CHRISTER SVENSSON, CLAUS R BAUMGARTEN, ULF PIPKORN, ULF ALKNER, \\ CARL G A PERSSON
}

From the Departments of Otorhinolaryngology and Clinical Pharmacology, University Hospital, University of Lund, and the Departments of Bioanalysis and Pharmacology, Draco, Lund, Sweden; and the Department of Clinical Immunology, Klinikum Rudolf Virschow, Freie Universität Berlin, Berlin, German Federal Republic

ABSTRACT Plasma exudation is one cardinal factor in airways defence and inflammation. In inflammatory airway diseases such as rhinitis and asthma, however, plama leakage may also have a pathogenetic role. Experimental data from animals indicate that highly sensitive, active, and reversible processes regulate the vascular and mucosal permeability to macromolecules. With the use of a nasal lavage model for the recovery of liquids on the mucosal surface the effect of histamine on the macromolecular permeability of the airway endothelial-epithelial barriers was studied in normal subjects. The concentrations of albumin, kinins, and $N-\alpha-\beta$-tosyl-L-arginine-methyl esterase (TAME) in nasal lavage fluid were measured and nasal symptoms assessed by a scoring technique. The reproducibility of three repeated challenges with 30 minute intervals on the same day was studied in 12 subjects and compared with the same procedure (three challenges) on a different day. Sneezing decreased significantly $(p<0.05)$ after the first histamine challenge but was maintained thereafter. Otherwise, the mean values for symptoms and for markers of vascular leakage were very similar both for the three challenges in the same session and for the two challenge sessions on a different day. Sneezing, blockage, and secretions were associated with increased concentrations of TAME esterase (maximum $9000 \mathrm{cpm} / \mathrm{ml})$, kinins $(1.4 \mathrm{ng} / \mathrm{ml})$, and albumin $(0.3 \mathrm{~g} / \mathrm{l})$ in lavage fluid. Both the symptoms and the measures of plasma exudation were reversible and reproducible in the three repeat histamine challenges and at two challenge sessions on different days. These findings support the view that non-injurious, active processes regulate the inflammatory flow of macromolecules across airways endothelial-epithelial barriers. The present experimental approach would be suitable for studies of the modulatory effects of inflammatory stimulus induced plasma leakage and symptoms in human airways.

\section{Introduction}

Plasma exudation has long been known to be a cardinal factor in inflammation, the exuded plasma and its potent peptide products passing through the inflamed epithelial lining of cavity organs to be recovered on the mucosal surface. In inflammatory airway diseases such as rhinitis and asthma, however, a pathogenetic role of plasma leakage has been little emphasised '; in current discussions of mucosal defence this inflammatory passage of plasma is frequently referred to as a passive leakage across injured mucosal

Address for reprint requests: Dr Ulf Pipkorn, ENT Department, University Hospital, 22185 Lund, Sweden.

Accepted 3 November 1988 barriers, its role being seen only as a secondary line of defence. ${ }^{2}$ It has been suggested, for example, that because a dose of histamine induces substantial plasma exudation it is "highly unphysiologic" and less relevant for studies of the pharmacology of airway mucosa. ${ }^{3}$ This view seems to be at variance with recent experimental findings, which show that highly sensitive, active, and reversible processes regulate vascular and mucosal permeability to macromolecules. ${ }^{4-7}$

A role for exuded plasma proteins and peptides in rhinitis and asthma is supported by a substantial accumulation of data. Plasma exudation tracers sampled at the mucosal surface may be increased under baseline disease conditions in addition to showing a correlation with symptom induction and prevention. In these respects exuded plasma may be a better 
correlate of the disease state than several cellular mediators. ${ }^{8-12}$

We have now used histamine to study how frequently and reproducibly plasma exudation can be induced in human airways. This amine has direct effects on barrier cells, ${ }^{67}$ is a mediator of allergic rhinitis and asthma, ${ }^{13}$ and is widely used as an inhalational agent in studies of hyperresponsiveness in patients with airways disease..$^{145} \mathrm{We}$ have applied the challenge to nasal airways as surface liquids can be sampled readily from this area.$^{14}$ Adequate techniques are lacking for selective and non-traumatic sampling of the tracheobronchial mucosal fluid. ${ }^{16}$ Animal studies have shown that histamine induces plasma leakage in tracheobronchial airways ${ }^{13}$ but the possibility that histamine has this activity in nasal mucosa in man has rarely been mentioned. ${ }^{317}$ The present study examined plasma exudation and symptoms occurring in response to a fixed dose of histamine applied to the nasal mucosa at half hour intervals. We also studied the reproducibility of the effects induced by three histamine applications repeated at $\mathbf{3 0}$ minute intervals.

\section{Methods}

\section{SUBJECTS}

Twelve normal subjects (nine male, three female) were recruited, ranging in age from 24 to 42 (mean age 31 ) years. None had a history of allergic nasal disease or had any nasal complaint at the time of the study. No drugs were allowed during the study. Informed consent was obtained from each individual and the study was approved by the ethics committee of the University of Lund.

\section{NASAL CHALLENGE PROCEDURE}

Nasal fluid was collected by lavaging the nose with $5 \mathrm{ml}$ aliquots of normal saline $(0.9 \%)$ instilled into each nostril while the head was flexed backwards $30^{\circ}$ from the horizontal. ${ }^{18}$ This position was maintained for 10 seconds while the subject refrained from

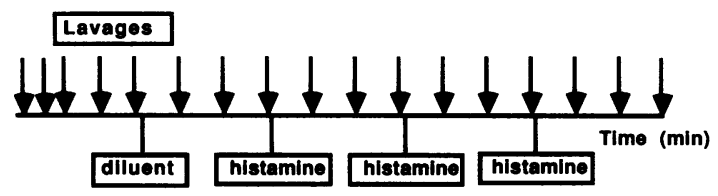

Fig 1 Schematic flow chart of the challenge model used. The arrows above the line indicate lavages. After three quick lavages (Nos 2 and 3 discarded) lavages were performed at 10 minute intervals. Nasal symptoms were assessed immediately before each lavage. Lavage 4 was followed by challenge with diluent and lavages 6,9 , and 12 by challenge with $1 \mathrm{mg}$ histamine. breathing and swallowing. On leaning forward the subjects expelled the lavage fluid into a container. $\frac{\vec{\sigma}}{0}$ Nasal liquids delivered in association with sneezes $\frac{C}{0}$ were added to the appropriate lavage fluid sample. The $\overline{\bar{c}}$ protocol (fig 1) included three prechallenge lavages $\overparen{\Phi}$ with saline to reduce the cell free mediators present $\stackrel{\circ}{\sim}$ initially in nasal secretions to a stable baseline. The ${ }^{\infty}$ fluid from lavages 2 and 3 was discarded. Further $\vec{O}$ lavages were then performed at 10 minute intervals. $\vec{\overrightarrow{ }}$ Immediately after the fifth lavage (at 30 minutes) each ${ }_{\sigma}^{\omega}$ nostril was challenged with the diluent used for $\vec{x}$ histamine to control for the delivery system. This was followed by three lavages at 10 minute intervals. $\Rightarrow$ Thereafter each nostril was challenged with $0.5 \mathrm{mg}_{\overrightarrow{-}}^{-}$ histamine hydrochloride in a solution of $0.9 \%$ sodium $\omega$ chloride and $0.25 \%$ human serum albumin. This was음 followed by three further lavages at 10 minuteintervals. The histamine challenge followed by the three lavages was then repeated twice. Each subject? was given the three doses of histamine on two occasions separated by at least a week. The lavage fluid $\vec{c}$ that returned was measured and processed for theog chemical analysis described below.

\section{ASSESSMENT OF SYMPTOMS}

A symptom questionnaire was given to subjects duringō the challenge procedure. A five point scale from 0 to 40 $(0=$ no symptoms, $4=$ severe symptoms) was used $\stackrel{\mathbb{Q}}{\varrho}$ for assessing nasal stuffiness, nasal secretion, and $\overrightarrow{\hat{O}}$ sneezing.

\section{ANALYTICAL ASSAYS}

Kinins were measured by a radioimmunoassay ${ }^{10}$ sen sitive to $20 \mathrm{pg} / \mathrm{ml}$ with an intraassay coefficient of 0 variation of $5 \%$ and an intercoefficient of $10 \% . N-\alpha-\beta-\frac{\tilde{\nu}}{x}$ tosyl-L-arginine-methyl esterase (TAME) activity was윽 measured by a radiochemical assay essentially as described by Imanari $^{19}$ and adapted for the nasalo lavage procedure. Albumin was measured with a radioimmunoassay sensitive to $6.25 \mathrm{ng} / \mathrm{ml}$ with anti-음 albumin (DAKOPATTS, Copenhagen) and commer- $\rightarrow$ cial standard (Calbiochem, San Diego, California). 을 Iodination was made with the lactoperoxidasen method $^{20}$ to a specific activity of $2 \mathrm{mCi} / \mathrm{nmol}$. The intraassay coefficient of variation was $5 \%$ and the intercoefficient $10 \%$.

STATISTICAL ANALYSES

Statistical evaluation was performed on a microcomputer (Macintosh, Apple Computer, Cupertino, USA) ${ }^{+}$ using a software package ('Statview $512+$ by Brain- $-\frac{T}{\circ}$ power Inc, Calabasas, California). The measurements that followed the three histamine challenges were used? to assess reproducibility on the same day (threes observations) and between days (the first observation? and the third observation were analysed separately) $\Omega$ 

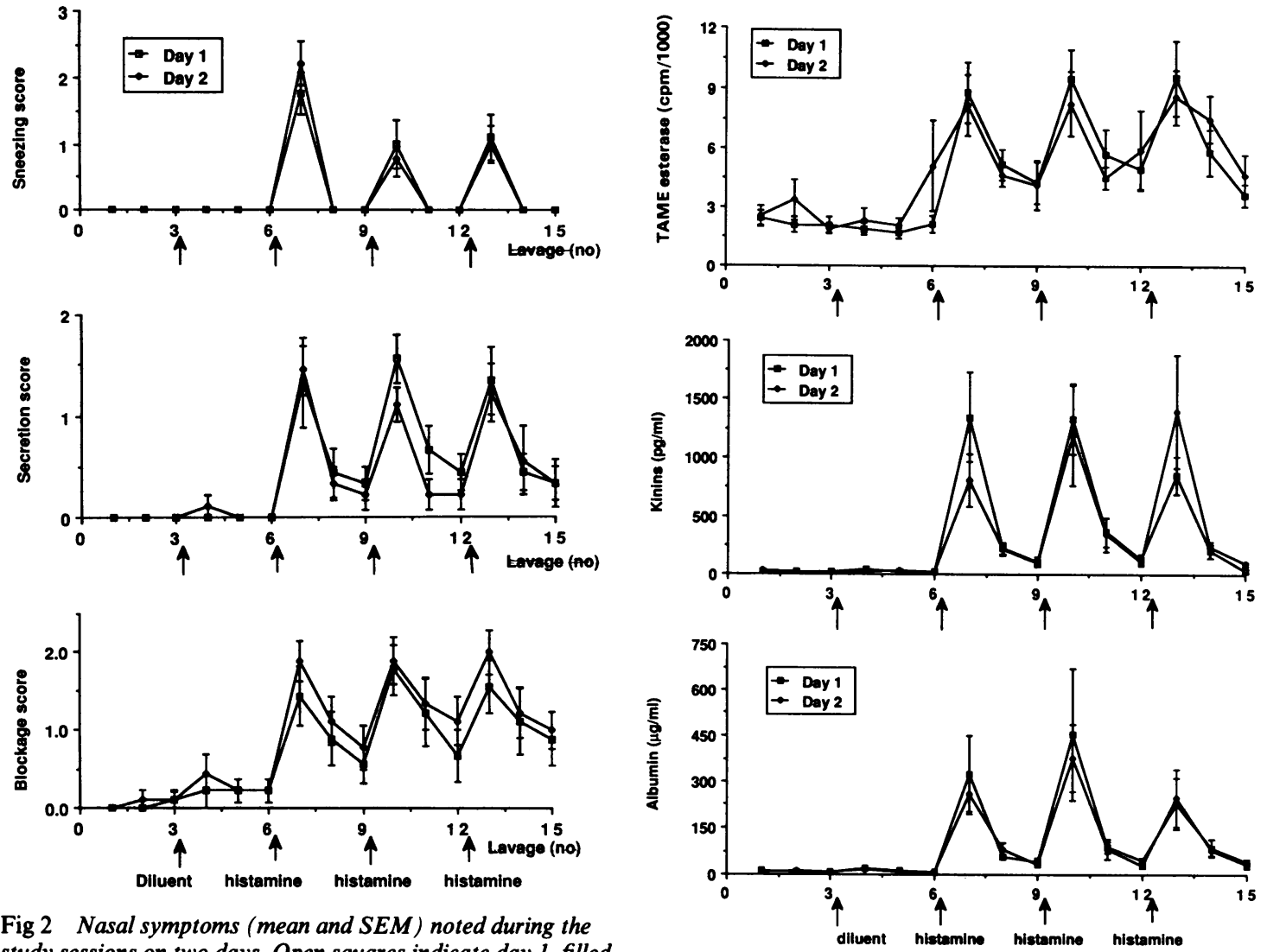

Fig 2 Nasal symptoms (mean and SEM) noted during the study sessions on two days. Open squares indicate day 1, filled squares day 2; the numbers on the horizontal axis are lavage numbers. The mean values for the two days are almost identical. Repeat histamine challenges on the same day resulted in similar symptoms for blockage and secretion; sneezing was less after the second and third challenge.

The observations after the three histamine challenges were further compared by means of Friedman's test. Comparison between the two days were made with Student's $t$ test. P values less than 0.05 were considered significant (two tailed test).

\section{Results}

Data from all 12 subjects who entered the study were

Table 1 Reproducibility of nasal symptoms

\begin{tabular}{|c|c|c|c|}
\hline \multirow{3}{*}{$\begin{array}{l}\text { Nasal } \\
\text { symptom }\end{array}$} & \multicolumn{3}{|c|}{ Mean coefficient of variation (\%) } \\
\hline & \multirow{2}{*}{$\begin{array}{l}\text { Intra-session } \\
3 \text { peaks }\end{array}$} & \multicolumn{2}{|c|}{ Inter-session } \\
\hline & & Ist peak & 3 peaks \\
\hline $\begin{array}{l}\text { Secretion } \\
\text { Blockage } \\
\text { Sneezes }\end{array}$ & $\begin{array}{l}42 \\
38 \\
56\end{array}$ & $\begin{array}{l}48 \\
42 \\
25\end{array}$ & $\begin{array}{l}48 \\
45 \\
27\end{array}$ \\
\hline
\end{tabular}

Fig 3 Concentration of plasma markers (means and SEM) found during the studies on the two days. Open squares indicate day 1 , filled squares day 2; the numbers on the horizontal axis are lavage numbers. No differences were noted between the two days and the repeat histamine challenges on the same day produced similar peak values for the three markers.

available for analysis. The histamine challenges and nasal lavages were well tolerated. The intranasal challenge with histamine induced all three major nasal symptoms - sneeze, nasal blockage, and nasal secretion. The nasal symptoms obtained on the two challenge days are shown in figure 2 , and the mean coefficient of variation for symptoms in the same (intra) session and between (inter) the two challenge sessions in table 1 . The challenge with diluent alone did not induce any nasal symptoms. The mean symptom score for secretion and blockage were very similar on the three occasions on the same day and on two different days. The mean score for sneeze was very similar on the two challenge days, yielding the lowest coefficient of variation of the three symptoms. Sneezing showed a constant time relationship to histamine 
Table 2 Reproducibility of the biochemical marker measurements

\begin{tabular}{llll}
\hline & \multicolumn{3}{l}{ Mean coefficient of variation (\%) } \\
\cline { 2 - 4 } Biochemical & $\begin{array}{l}\text { Intra-session } \\
\text { Marker }\end{array}$ & 3 peaks & Inter-session \\
\cline { 2 - 4 } & 32 & 42 & 35 \\
\hline TAME esterase & 32 & 43 & 40 \\
Bradykinin & 32 & 44 & 45 \\
Albumin & 36 & peaks \\
\hline
\end{tabular}

challenge, appearing two to six minutes after the challenge. The secretion score had almost returned to baseline by 10 minutes, whereas the blockage score was raised before the second and third histamine provocations. The challenge induced peak responses were nevertheless quite separate and reached the same height (fig 2). The initial histamine challenge produced more sneezes $(p<0.05)$ than the second and third challenges, which produced an equal mean sneeze score.

The result from the measurements of solutes in nasal secretions are presented in figure 3 . The recovery of the instilled lavage fluid was always over $80 \%$. The levels of TAME esterase, kinins and albumin showed a similar pattern to that seen with the nasal symptoms. There was a low baseline TAME esterase activity before the challenge procedure. Each histamine provocation significantly increased the TAME esterase activity to about the same mean peak level. The activity before the second and third histamine challenges was twice the baseline activity before any challenge. Histamine also increased the concentration of kinins and albumin in the lavage samples, but these solutes returned almost to baseline values between the provocations (fig 3). The coefficient of variation for the histamine induced appearance of these solutes in lavage liquids are shown in table 2 .

The correlation coefficients for the individual values obtained for symptoms and histamine induced solutes obtained on the first occasion are given in table 3.

\section{Discussion}

This study shows that the endothelial-epithelial passage of tracers of plasma exudation could be induced in a consistent and reversible way by topical applica- $\overrightarrow{7}$ tion of histamine on human nasal airways. The dose of histamine used produced appreciable blockage of the nasal airways. This did not impede the lavage $\overline{\bar{n}}$ procedure, which could be performed with satisfactory recovery of instilled fluid. Vasoactive nasal $\varrho$ decongestants, which may affect plasma exudation byő reducing blood flow and may release mediators via an $\vec{\circ}$ unknown mechanism, ${ }^{21}$ were not needed. The two $5 \mathrm{ml}-$ aliquots of lavage fluid used in the study may havew irrigated a portion of the pharynx as well as the nasal cavity, ${ }^{22}$ but an effective rinse of the area of airwayx mucosa exposed to histamine was achieved.

Histamine induced significant increases in kinins (bradykinin and lysylbradykinin are measured $\vec{\omega}$ together) and TAME esterase activity as well aso albumin in the fluid obtained from the mucosalsurface. It is interesting that kinins are being produced to such an extent after stimulation with histamine only. Kinins in nasal liquid have previously beeng associated with provocations such as exposure to allergen or cold, dry air and rhinovirus induced colds $\vec{\infty}$ which also produce appreciable nasal symptoms. ${ }^{1123}$ In 6 contrast, mast cell mediator release in human airways may occur without symptoms or increased concentrations of kinins."

Allergen provocations have been shown to produce leakage of plasma kininogens into nasal liquids, thus providing substrate for kinin forming enzymes. ${ }^{8}$ His- $\overrightarrow{7}$ tamine in this study is likely to have caused plasma kininogens to leak across the vascular-mucosab barriers. The respective roles of plasma and glandularo kallikreins in kinin formation during histamine challenge is not known; both may have contributed, aso has been shown in experimentally induced allergic rhinitis. ${ }^{17}$ About $70 \%$ of the TAME esterase activityo found in lavage fluid obtained after allergen challenge is consistent with the plasma kallikrein- $\alpha_{2}$ macroo globulin complex, other sources, including mast celß tryptase, being responsible for a lesser part of thiso activity. ${ }^{17}$ Histamine, which does not cause mast cell mediator release, appears to induce TAME esterase activity in nasal lavage fluid through the plasma kallikrein- $\alpha_{2}$ macroglobulin complex, which is devoidos of kininogenase activity. ${ }^{24}$

Table 3 Correlations* between values obtained for symptoms and plasma proteins during the first challenge session

\begin{tabular}{|c|c|c|c|c|c|c|}
\hline & $\begin{array}{l}T A M E \\
\text { secretion }\end{array}$ & Albumin & Kinins & Blockage & Sneezes & Secretion \\
\hline $\begin{array}{l}\text { TAME } \\
\text { Albumin } \\
\text { Bradykinin } \\
\text { Blockage } \\
\text { Sneezes } \\
\text { Secretion }\end{array}$ & $\begin{array}{l}1 \\
0.88 \\
0.9 \\
0.95 \\
0.80 \\
0.98\end{array}$ & $\begin{array}{l}1 \\
0.98 \\
0.84 \\
0.87 \\
0.94\end{array}$ & $\begin{array}{l}1 \\
0.83 \\
0.94 \\
0.95\end{array}$ & $\begin{array}{l}1 \\
0.69 \\
0.94\end{array}$ & $\begin{array}{l}1 \\
0.86\end{array}$ & 1 \\
\hline
\end{tabular}

*All correlations statistically significant $(p<0.001)$. 
The present limited measurements suggest that unrestricted plasma macromolecular flow into airway liquids has occurred in response to histamine. Molecules from 70000 (albumin) to 900000 daltons $\left(\alpha_{2}\right.$ macroglobulin) have passed across the endothelialepithelial linings, which normally provide a tight barrier at least to macromolecular movement. ${ }^{67} \mathrm{His}$ tamine induced leakage may therefore have been a bulk flow of plasma proteins across the vascular wall ${ }^{25}$ and mucosal epithelial lining. Widely varying protein systems would thus come in contact with negatively charged membranes and surfaces. The ensuing activation of plasma systems was in this study exemplified by kinin formation. Conceivably complement, coagulation, and other plasma systems also would have been activated, but this remains to be studied in detail.

This study showed consistent plasma leakage in response to an inflammatory mediator applied repeatedly at half hour intervals. Not only was the histamine induced plasma leakage rapidly induced and rapidly reversible but the airway vascular and mucosal responsiveness was unchanged when the challenge was repeated after 30 minutes. Further applications of histamine beyond three might have continued to produce consistent plasma leaks, as in animal experimental systems, where the microvascular barrier has been shown to respond reversibly and consistently to histamine applications every $30 \mathrm{~min}$ utes. ${ }^{726}$ Little is known about corresponding mucosal barrier mechanisms.

The present method measures the sum of macromolecular permeability across the microvascular endothelium and the mucosal epithelium. Macromolecular flow across both barriers is clearly increased promptly with the application of histamine. We cannot tell from the present data whether the epithelial permeability has the same time courses in change in permeability as the vascular barrier or whether the epithelium remained permeable after the initial histamine challenge. The epithelial passage of plasma is an important clearance route, reducing the tendency of mucosal oedema formation. ${ }^{12}$ Epithelial permeability to exuded plasma may be different from the permeability responsible for absorption of luminal macromolecules into airway tissue. Whether the increased mucosal permeability we have studied is bidirectional remains to be examined. Methacholine differs from histamine in not causing plasma exudation in nasal and tracheobronchial airways. ${ }^{327}$ This suggests that histamine induced neural cholinergic activation may not have contributed to the plasma exudation in this study. Tachykinergic nerves may also not have contributed since tachykinins, which act as potent inflammatory agents in guinea pigs, may not act thus in man. ${ }^{27}{ }^{28}$ Several pieces of experimental evidence, including receptor localisation, suggest that histamine exerts its effect directly on the vascular permeability regulating endothelial cells. ${ }^{47}$ The microvessels that consistently respond to an inflammatory stimulus such as histamine are the postcapillary venules. ${ }^{45725}$ The histamine induced venular permeability is known as an active endothelial mechanism, perhaps a contractional event, that is under physiological and pharmacological control. Clearly the present observation of histamine induced plasma leakage in human airways is consistent with the idea that non-injurious mucosal processes are concerned in the exudation of plasma.

The symptoms induced by histamine may be due to direct effects on target cells by plasma exudation, but may also in part be produced indirectly via complex neural and non-neural interactions. Histamine stimulates afferent rapidly adapting receptors and C fibre nerve endings, ${ }^{29}$ both of which may play a part in sneezing (and coughing). Exuded plasma products such as kinins also stimulate these afferent mechanisms $^{29}$ and might have participated in the sneeze inducing action of topical histamine. Sneezing was most pronounced with the first histamine challenge (fig 2). The second and third histamine applications, however, had about equal effects, indicating that tachyphylaxis of the sneezing mechanism was limited. This is in contrast to observations on repeated allergen provocations (roughly 40 minute intervals), where the sneezing response was substantially reduced. ${ }^{30}$ With frequently repeated allergen provocations we cannot expect consistent responses in terms of change either in biochemical variables or in symptoms because allergen induced effects have such variable time courses of monophasic and biphasic responses. ${ }^{3031}$ Allergen provocations may thus induce alterations in baseline values and in mucosal sensitivity to further provocations. Allergen induced plasma exudation is different in its characteristics from the histamine induced plasma exudation in our study.

Both the symptoms and the measures of plasma exudation were reasonably reproducible in repeat challenges with histamine and at repeat sessions of such challenges. This suggests that the present experimental approach is suitable for studies of modulatory effects of inflammatory stimulus induced plasma leakage and symptoms in human airways.

This study was supported in part by grants from the Swedish Medical Research Council (project 8308), the medical faculty of the University of Lund, and AB Draco, Lund.

\section{References}

1 Persson CGA. Role of plasma exudation in asthmatic airways. Lancet 1986;ii:1126-9.

2 Hansson L- $\AA$, Brandtzeg P. The mucosal defence system. 
In: Stiehm ER, Fulfginiti VA, eds. Immunological disorders of infants and children. Philadelphia: Saunders, 1980:137-64.

3 Brofelt S, Mygind N, Sörensen CH, Readman AS, Mariott C. Biochemical analysis of nasal secretions induced by methacholine, histamine and allergen provocations. Am Rev Respir Dis 1986;133:1138-42.

4 Majno G, Palade GE. Studies on inflammation $I$. J Biophys Biochem Cytol 1961;11:571-605.

5 Hurley JV. Acute inflammation. 2nd ed. Edinburgh: Churchill Livingstone, 1983.

6 Boucher RC, Ranga V, Paré PD, Inoue S, Moroz LA, Hogg JC. Effect of histamine and metacholine on guinea pig tracheal permeability to HRP. J Appl Physiol Respirat Environ Exerc Physiol 1978;45: 939-49.

7 Persson CGA, Svensjö E. Vascular responses and their suppression: drugs interfering with venular permeability. In: Bonta IL, Bray MA, Parnham MJ, eds. Handbook of inflammation. Vol 5. The pharmacology of inflammation. Amsterdam: Elsevier, 1985:61-81.

8 Baumgarten CR, Togias A, Naclerio RM, Norman PS, Lichtenstein LM, Proud D. Kininogens are generated following nasal challenge with allergen in allergic individuals but not non-allergic individuals $J$ Clin Invest 1985;76:191-7.

9 Pipkorn U, Proud D, Lichtenstein LM, et al. Effect of short-term systemic glucocorticoid treatment on human nasal mediator release after antigen challenge. J Clin Invest 1987;80:957-61.

10 Proud D, Togias A, Naclerio RM, Crush S, Norman PS, Lichtenstein LM. Kinins are generated in-vivo following nasal airway challenge of allergic individuals with allergen. J Clin Invest 1983;72:1678-85.

11 Proud D, Baumgarten CR. Kinins in nasal lavage fluids. In: Mygind N, Pipkorn U, eds. Allergic and vasomotor rhinitis: pathophysiological aspects. Copenhagen: Munksgaard, 1987:198-207.

12 Persson CGA. Plasma exudation and asthma. Lung 1988;166:1-23.

13 White MV, Slater JE, Kaliner MA. Histamine and asthma. Am Rev Respir Dis 1987;135:1166-76.

14 Pipkorn U, Bisgaard H, Wihl J-A. Nasal provocation testing and lavage technique. In: Mygind N, Pipkorn $\mathrm{U}$, eds. Allergic and vasomotor rhinitis. Pathophysiological aspects Copenhagen: Munksgaard, 1987: 149-64.

15 Hargreave FE, Woolcock AG. Airway responsiveness; measurement and interpretation. Mississauga, Canada: Astra Pharmaceuticals, 1985.

16 Reynolds HY. Bronchoalveolar lavage. Am Rev Respir Dis 1987;135:250-63.

17 Baumgarten CR, Nichols RC, Naclerio RM, Lichtenstein LM, Norman PS, Proud D. Plasma kallikrein during experimentally induced allergic rhinitis: role in kinin formation and contribution to TAME esterase activity in nasal secretions. J Immunol 1986;137: 977:82.
18 Naclerio RM, Meier HL, Kagey-Sobotka A, et al. $\overrightarrow{\bar{F}}$ Mediator release after nasal airway challenge with $\stackrel{\text { f }}{+}$ allergen. Am Rev Respir Dis 1983;128:597-602.

19 Imanari T, Kaizu T, Yoshida H, Yates K, Pierce JV, Pisano JJ. Radiochemical assays for human urinary, $\overline{\mathcal{G}}$ salivary, and plasma kallikreins. In: Pisano JJ, Austen $\mathbb{D}$ $\mathrm{KF}$, eds. Chemistry and biology of the kallikrein-kinin 음 system in health and disease. Washington DC: Govern- $\infty$ ment Printing Office, 1976:295-313. (Department of $\vec{\circ}$ Health, Education and Welfare publication No (NIH) 76-791.)

20 Thorell JI, Johansson BG. Enzymatic iodination of polypeptides to high activity. Biochim Biophys Acta 1971;251:363-9.

21 Devalia JL, Davies RJ. Histamine levels in nasal secre- $\stackrel{+}{+}$ tions: effect of methacholine and allergen. In: Mygind $\overrightarrow{.}$ N, Pipkorn U, eds Allergic and vasomotor rhinitis. $\vec{\omega}$ Pathophysiological aspects. Copenhagen: Munks- $\frac{}{\partial}$ gaard, 1987:179-88.

22 Bisgaard H, Krogsgaard OW, Mygind N. Measurement C of nasal secretion by ${ }^{99 m}$ Tc-albumin. Clin Sci 1987; 73:217-22.

23 Dolovich J, Backn J, Arbesman CC. Kinin-like activity in nasal secretions. Int Arch Allergy Appl Immunol 1970; $\vec{\oplus}$ 38:337-44.

24 Harpel PC. Human plasma alfa-2 macroglobulin an inhibitor for plasma kallikrein. J Exp Med 1970;132: 329-52.

25 Zweifach BW. Microvascular aspects of tissue injury. In: Zweifach BW, Grant L, McClusky RT, eds. The

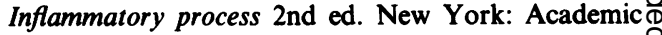
Press, 1973:3-46.

26 Svensjö E, Joyner WL. The effects of intermittent and $\overline{0}$ continuous stimulation of microvessels in the cheek pouch of hamsters with histamine and bradykinin on the development of venular leakage sites. Microcirc? Endothel Lymphatics 1984;1:381-96.

27 Persson CGA, Erjefält I. Non-neural and neural regula-ō tion of airway microvascular leakage of macromolecules. In: Kaliner MA, Barnes P, eds. Lung biology in health and disease. Neural regulation of the airways in health and disease. New York: M Dekker, 1988:523-50.

28 Karlsson G, Pipkorn U. Substance $P$ and the human nasal mucociliary activity. Eur $J$ Clin Pharmacolf 1986;30:355-7.

29 Coleridge HM, Coleridge JGC. Reflexes evoked from은 tracheobronchial tree and lungs. Handbook of Physiology. Section 3. The respiratory system. Vol 2. Bethesda, Maryland: American Physiological Society, $N$ 1986:2-110.

30 Togias AG, Naclerio RM, Warner J, et al. Demonstra- $\omega$ tion of inhibition of mediator release from human mast cells by azatadine base. In vivo and in vitro evaluation? JAMA 1986;255:225-9.

31 Naclerio RM, Proud D, Togias AG, et al. Inflammatory: mediators in late antigen-induced rhinitis. $N$ Englo J Med 1985;313:65-70. 